\title{
EFEITO DALUZ, TEMPERATURA E ESTRESSE HÍDRICO NO POTENCIAL FISIOLÓGICO DE SEMENTES DE FUNCHO ${ }^{1}$
}

\author{
RAQUELSTEFANELLO², DANTON CAMACHO GARCIA ${ }^{3}$, NILSONLEMOS DEMENEZES ${ }^{3}$, \\ MARLOVE FÁTIMABRIÃO MUNIZ4 ${ }^{4}$, CÁTIA FERNANDA WRASSE ${ }^{5}$
}

\begin{abstract}
RESUMO - O objetivo deste trabalho foi avaliar os efeitos da luz, temperatura e estresse hídrico no potencial fisiológico de sementes de funcho. O experimento foi conduzido em duas etapas. $\mathrm{Na}$ etapa I, as sementes foram semeadas sobre papel nas temperaturas constantes de $20,25,30^{\circ} \mathrm{C} \mathrm{e}$ alternada de $20-30^{\circ} \mathrm{C}$ na presença e ausência de luz. Na etapa II, as sementes foram colocadas sobre papel embebido em solução aquosa de polietileno glicol (PEG 6000) nos potenciais osmóticos correspondentes a zero; $-0,05 ;-0,10 ;-0,15 ;-0,20 ;-0,25 ;-0,30 \mathrm{MPa}$. O delineamento utilizado foi o inteiramente casualizado com quatro repetições. Conforme os resultados pode-se concluir que a germinação das sementes de funcho ocorre tanto na presença quanto na ausência de luz.. As sementes de funcho, germinam melhor nas temperaturas constantes de 20, 25 e e alternada de 20$30^{\circ} \mathrm{C}$ e a temperatura de $30^{\circ} \mathrm{C}$ não é adequada para o teste de germinação. A diminuição dos potenciais osmóticos com polietileno glicol 6000 , a partir de $-0,1 \mathrm{MPa}$, reduz drasticamente a germinação e o vigor das sementes de funcho, sendo o vigor mais afetado que a germinação.
\end{abstract}

Termos para indexação: Foeniculum vulgare, germinação, vigor.

\section{THE EFFECT OF LIGHT, TEMPERATURE AND HYDRIC STRESS ON THE PHYSIOLOGIC POTENTIALITY OF FENNEL SEEDS}

\begin{abstract}
The objective of this study was to evaluate the effects of light, temperature and hydric stress on the germination and vitality of fennel seeds.. First, the seeds were sowed on paper at constant temperatures of $20,25,30^{\circ} \mathrm{C}$ or alternating temperatures of $20-30^{\circ} \mathrm{C}$ in the presence or absence of light. In a second step, seeds were kept on paper in aqueous polyethylene glicol (PEG 6000 ) at the osmotic potentials equivalent to zero; $-0,05 ;-0,10 ;-0,15 ;-0,20 ;-0,25 ;-0,30 \mathrm{MPa}$. According to the results, it was possible to conclude that germination of fennel seeds occurred in presence or absence light. The fennel seeds germinated better at constant temperatures of 20 and $25^{\circ} \mathrm{C}$ but $30^{\circ} \mathrm{C}$ was not useful for the germination test. The decrease in the osmotic potentials reduced the germination and vigor of fennel seeds, and vigor was more affected than germination. The germination was drastically reduced, starting at $-0,1 \mathrm{MPa}$ for fennel when there was a decrease in the osmotic potentials with polyethylene glicol 6000 .
\end{abstract}

Index terms: Foeniculum vulgare, germination, hydric stress.

\footnotetext{
${ }^{1}$ Submetido em 18/05/2005. Aceito para publicação em 22/12/2005. Parte da dissertação de mestrado apresentada ao PPGA/UFSM;

2 Bióloga, MSc. em Agronomia, Depto Fitotecnia, UFSM, raquelstefanello@yahoo.com.br;

${ }^{3}$ Eng $^{\circ}$ Agrônomo, Dr., Prof. Adjunto,Depto. Fitotecnia, UFSM, 97105-
}

900, Santa Maria - RS, danton@smail.ufsm.br; nlmenezes@samail.ufsm.br

${ }^{4}$ Eng $^{\circ}$ Agr $^{\circ}$, Dra., Prof ${ }^{\mathrm{a}}$. Adjunto, Depto. de Defesa Fitossanitária, UFSM, CEP: 97105-900, Santa Maria - RS;

${ }^{5}$ Eng ${ }^{\mathrm{a}}$ Agrônoma, mestranda do PPG em Agronomia, Depto Fitotecnia, UFSM. 


\section{INTRODUÇÃO}

O funcho (Foeniculum vulgare Miller) é uma espécie medicinal, nativa da Europa e amplamente cultivada em todo o Brasil. Apresenta flores amarelas, dispostas em umbelas e os frutos são diaquênios (Lorenzi e Matos, 2002). Possui propriedades carminativas, digestivas e diuréticas. O óleo essencial do funcho é utilizado na fabricação de licores e perfumes. As sementes são utilizadas na confeitaria como aromatizantes em pães, bolos e biscoitos (Martins et al., 1998).

O processo germinativo inicia-se com a embebição e a conseqüente retomada das atividades paralisadas por ocasião da maturação fisiológica das sementes, sendo para isto necessários alguns requisitos fundamentais como as sementes estarem viáveis e as condições ambientais serem favoráveis (Carvalho e Nakagawa, 2000).

Para que uma semente viável possa germinar são necessários: suprimento de água em quantidade suficiente; temperatura; substrato e uma composição de gases adequada, bem como de luz para determinadas espécies (Carvalho e Nakagawa, 2000). O grau de exigência desses fatores é variável entre as espécies e determinado pelo genótipo e pelas condições ambientais prevalecentes durante a germinação das sementes (Mayer e Poljakoff-Mayber, 1989).

O teste de germinação, realizado em condições ótimas de laboratório, consiste em determinar o potencial germinativo de um dado lote de forma a avaliar a qualidade fisiológica das sementes para fins de semeadura e produção de mudas (Brasil, 1992; Carvalho e Nakagawa, 2000). Este teste permite quantificar o valor das sementes vivas, capazes de produzir plântulas normais sob condições favoráveis de campo. Por outro lado, no campo, as sementes podem estar sujeitas a situações adversas como temperatura inadequada, excesso ou déficit hídrico, ataque de microrganismos, de modo que a percentagem de emergência das plântulas em campo é geralmente menor que a obtida no teste de germinação. Assim, para complementar o teste de germinação, podem ser utilizados os testes de vigor que irão avaliar o potencial de emergência das sementes e o rápido desenvolvimento das plântulas normais sob ampla diversidade de condições do ambiente (AOSA, 1983).

Apesar do aumento considerável de conhecimento relativo à análise de sementes de espécies medicinais, gerados por pesquisas nestas duas últimas décadas, a maioria delas carece de subsídios básicos referentes às condições ideais de germinação e informações referentes ao vigor. Este fato pode ser comprovado através das Regras para Análise de Sementes
(Brasil, 1992), onde são encontradas poucas informações sobre a metodologia para análise de sementes dessas espécies que são merecedoras de vários estudos, não apenas quanto à identificação correta do princípio ativo fitoterápico, como, também, a avaliação dos efeitos de fatores como luz, temperatura, água e substrato no comportamento germinativo.

Em vista destas considerações, o presente trabalho teve como objetivo avaliar os efeitos da luz, da temperatura e do estresse hídrico no potencial fisiológico de sementes de funcho.

\section{MATERIAL E MÉTODOS}

O trabalho experimental foi conduzido no Laboratório Didático e de Pesquisas em Sementes, do Departamento de Fitotecnia, na Universidade Federal de Santa Maria, RS.

Foram utilizadas sementes de funcho (Foeniculum vulgare) adquiridas de uma empresa tradicional em produção e comercialização de sementes.

Para avaliações do efeito da luz e da temperatura sobre o potencial fisiológico, as sementes de funcho foram submetidas à presença ou ausência de luz nas temperaturas constantes de 20,25 e $30^{\circ} \mathrm{C}$ e alternada de $20-30^{\circ} \mathrm{C}$.

$\mathrm{Na}$ presença de luz, as sementes foram colocadas em câmara de germinação, com regime de $8 \mathrm{~h}$ de luz e $16 \mathrm{~h}$ sem luz. Na ausência de luz, as sementes foram semeadas em sala iluminada com luz verde e mantidas no escuro durante todo o teste, envolvendo-se as caixas plásticas de germinação com papel alumínio. A condição com iluminação foi obtida nas câmaras de germinação pela utilização de quatro lâmpadas fluorescentes do tipo luz do dia $20 \mathrm{w}$, com densidade de fluxo radiante na altura das caixas de $15 \mathrm{mmol} \cdot \mathrm{m}^{-2} \cdot \mathrm{s}^{-1}$ (Cardoso, 1995).

O potencial fisiológico foi avaliado através dos seguintes testes:

Germinação: realizado com quatro repetições de 100 sementes, distribuídas em caixa plástica do tipo gerbox, sobre três folhas de papel filtro umedecidas com água destilada na proporção de 2,5 vezes o peso do papel substrato. O teste foi conduzido nas diferentes temperaturas, sendo as contagens realizadas aos 7 e 14 dias após a semeadura, conforme recomendação de Brasil (1992). Os resultados foram expressos em percentagem média de plântulas normais.

Primeira contagem: realizada conjuntamente com o teste de germinação, onde se determinou a percentagem de plântulas normais no sétimo dia após a instalação do teste, conforme recomendação de Brasil (1992). 
Índice de velocidade de germinação (IVG): o teste foi implantado do mesmo modo que o teste padrão de germinação. As contagens das sementes germinadas foram efetuadas diariamente, no mesmo horário, durante o período de 14 dias, procedendo-se o reumedecimento do substrato com quantidade única de água destilada, no sétimo dia, após o início do teste. $\mathrm{O}$ critério de germinação foi a protrusão radicular. $\mathrm{O}$ índice de velocidade de germinação foi calculado como a média dos valores obtidos para as quatro repetições de 100 sementes, empregando-se a fórmula de Maguire (1962), sugerida por Nakagawa (1999).

$$
\begin{aligned}
& \text { IVG }=\mathrm{G}_{1} / \mathrm{N}_{1}+\mathrm{G}_{2} / \mathrm{N}_{2}+\ldots+\mathrm{G}_{\mathrm{n}} / \mathrm{N}_{\mathrm{n}} \\
& \text { Onde: }
\end{aligned}
$$

IVG = Índice de velocidade de germinação

$\mathrm{G}_{1}, \mathrm{G}_{2}, \mathrm{G}_{\mathrm{n}}=$ número de sementes germinadas computadas no primeiro dia, segundo dia e último dia.

$\mathrm{N}_{1}, \mathrm{~N}_{2}, \mathrm{~N}_{\mathrm{n}}=$ número de dias da semeadura à primeira, segunda e à última contagem.

Comprimento das plântulas: avaliou-se o comprimento médio das plântulas normais obtidas a partir da semeadura de quatro repetições de 10 sementes. Os rolos de papel contendo as sementes permaneceram em câmara de germinação por sete dias, quando então, se avaliou o comprimento total das plântulas, com o auxílio de uma régua milimetrada. O comprimento médio das plântulas foi obtido somando-se as medidas de cada repetição e dividindo-se pelo número de plântulas normais mensuradas, com resultados expressos em centímetros, conforme descrito por Nakagawa (1999).

Massa seca das plântulas: empregou-se quatro repetições de 10 plântulas, provenientes do teste anterior, mantidas em sacos de papel, em estufa a $60^{\circ} \mathrm{C}$, até a obtenção de massa constante (48h). Em seguida, as repetições foram pesadas em balança de precisão $0,001 \mathrm{~g}$, sendo os resultados expressos em miligramas por plântula, conforme Nakagawa (1999).

Estresse hídrico: avaliado por meio do teste de germinação, primeira contagem e índice de velocidade de germinação, conforme descritos acima. Utilizou-se a temperatura constante de $20^{\circ} \mathrm{C}$ em presença de luz e o substrato papel foi embebido com soluções de polietileno glicol (PEG 6000) nos potenciais osmóticos correspondentes a zero; $-0,05 ;-0,10 ;-0,15 ;-0,20 ;-0,25 ;-0,30 \mathrm{MPa}$. O nível zero correspondeu à testemunha (controle), onde se utilizou água destilada.

A quantidade de PEG 6000 necessária para obtenção dos potenciais osmóticos foi obtida com base em Michel e Kaufman (1973) e Villela et al. (1991).
Análise estatística: nas duas etapas, o delineamento experimental utilizado foi o inteiramente casualizado, onde, na primeira, os tratamentos constituíram um fatorial 4 × 2 (4 temperaturas $\mathrm{x}$ presença ou ausência de luz) com quatro repetições de 100 sementes, e na segunda, 6 tratamentos constituídos pelos níveis de potenciais osmóticos. As variáveis germinação e primeira contagem foram transformadas em $\operatorname{arc~sen}(X / 100)^{1 / 2}$ (Storck et al., 2000). Para análise da variância empregou-se o teste $\mathrm{F}$ e, quando este foi significativo, as comparações entre as médias dos tratamentos foram efetuadas pelo teste de Tukey, ao nível de 5\% de probabilidade (variáveis qualitativas) e por regressão polinomial (variáveis quantitativas), utilizado-se o programa computacional SANEST (Zonta et al., 1986).

\section{RESULTADOS E DISCUSSÃO}

Etapa I: Efeito da luz e da temperatura sobre o potencial fisiológico das sementes de funcho.

Na Tabela 1, são apresentados os resultados referentes à percentagem de germinação das sementes de funcho submetidas a diferentes temperaturas na presença e na ausência de luz. Observa-se que as sementes apresentaram comportamento indiferente à luz. Essa espécie, provavelmente, apresenta a forma de fitocromo fiA, que controla a germinação através da resposta de fluência muito baixa (Takaki, 2001) ou pode ser classificada como insensível à luz, uma vez que germina tanto na presença como na ausência de luz (Labouriau, 1983).

Em relação à temperatura, os maiores percentuais de germinação foram observados nas temperaturas constantes de 20 e $25^{\circ} \mathrm{C}$ e alternada de $20-30^{\circ} \mathrm{C}$. Resultados semelhantes foram obtidos na germinação de sementes de marcela (Ikuta

TABELA1 - Germinação de sementes de funcho (\%), submetidas a diferentes temperaturas na presença e na ausência de luz. Santa Maria, RS. 2004.

\begin{tabular}{ccc}
\hline Temperatura & Presença de luz & Ausência de luz \\
\hline $20^{\circ} \mathrm{C}$ & $85 \mathrm{aA}^{*}$ & $84 \mathrm{aA}^{*}$ \\
$25^{\circ} \mathrm{C}$ & $85 \mathrm{aA}$ & $82 \mathrm{aA}$ \\
$20-30^{\circ} \mathrm{C}$ & $81 \mathrm{aA}$ & $81 \mathrm{aA}$ \\
$30^{\circ} \mathrm{C}$ & $51 \mathrm{bB}$ & $63 \mathrm{bA}$ \\
\hline Média geral & & 76,56 \\
$\mathrm{CV}(\%)$ & 5,61 \\
\hline
\end{tabular}

* Médias seguidas de mesma letra, minúscula em cada coluna, e, maiúscula em cada linha, não diferem entre si, pelo teste de Tukey, a 5\% de probabilidade. 
e Barros, 1996), alface (Menezes et al., 2000), cenoura (Carneiro e Guedes, 1992) e anis (Takarashi et al., 2000; Teixeira et al., 2003).

Observa-se, ainda, que a alternância da temperatura também favoreceu a germinação. Esses resultados estão de acordo e, podem complementar, os recomendados por Brasil (1992) e Meneghello (2002), que indicaram a temperatura de $20-30^{\circ} \mathrm{C}$ para a germinação de sementes de funcho. Essa temperatura alternada também é indicada para a germinação de sementes de outras espécies como aipo, endro, cominho e salsa (Brasil, 1992). Essa necessidade de alternância da temperatura pode estar associada à dormência das sementes, embora possa, também, acelerar a germinação de sementes não dormentes (Copeland e McDonald, 1995).

Na temperatura de $30^{\circ} \mathrm{C}$, a maioria das plântulas obtidas foi anormal apresentando a raiz primária pouco desenvolvida, epicótilo curto e necrosado. Além dos efeitos observados, as altas temperaturas podem levar à dormência térmica ou até mesmo a perda da viabilidade das sementes através do estresse térmico (Vidaver e Hsiao, 1975). Na maioria dos casos, o estresse térmico retarda o desenvolvimento do processo germinativo, podendo suprimi-lo em sementes quiescentes ou para as que já haviam iniciado sua germinação (Pollock e Ross, 1972).

Na Tabela 2 são apresentados os resultados referentes à primeira contagem do teste de germinação, onde se observa que sobre as sementes de funcho, houve efeito significativo entre os fatores luz, temperatura e interação entre luz e temperatura. Os melhores resultados da primeira contagem do teste de germinação foram observados na ausência de luz e nas temperaturas constantes de 20 e $25^{\circ} \mathrm{C}$ e alternada de 20-30 ${ }^{\circ} \mathrm{C}$, sendo que, na ausência de luz, apenas na temperatura

TABELA 2. Primeira contagem do teste de germinação (\%) de sementes de funcho, submetidas a diferentes temperaturas na presença e na ausência de luz. Santa Maria, RS. 2004.

\begin{tabular}{ccc}
\hline Espécie & \multicolumn{2}{c}{ Funcho } \\
\hline Temperatura & Presença de luz & Ausência de luz \\
\hline $20^{\circ} \mathrm{C}$ & $38 \mathrm{bB}^{*}$ & $61 \mathrm{aA}^{*}$ \\
$25^{\circ} \mathrm{C}$ & $50 \mathrm{aB}$ & $70 \mathrm{aA}$ \\
$20-30^{\circ} \mathrm{C}$ & $56 \mathrm{aA}$ & $65 \mathrm{aA}$ \\
$30^{\circ} \mathrm{C}$ & $4 \mathrm{cB}$ & $28 \mathrm{bA}$ \\
\hline Média geral & & 46,62 \\
$\mathrm{CV}(\%)$ & & 11,31
\end{tabular}

* Médias seguidas de mesma letra, minúscula em cada coluna, e, maiúscula em cada linha, não diferem entre si, pelo teste de Tukey, a 5\% de probabilidade. de $30^{\circ} \mathrm{C}$, houve menor número de plântulas normais.

Conforme Bewley e Black (1994), a temperatura afeta tanto a capacidade como a velocidade de germinação. As sementes têm a capacidade de germinar em uma determinada faixa de temperatura, característica para cada espécie, mas o tempo necessário para se obter à percentagem máxima de germinação é dependente da temperatura. As temperaturas inferiores ou superiores à ótima tendem a reduzir a velocidade do processo germinativo, expondo as plântulas por maior período a fatores adversos, o que pode levar à redução no total de germinação (Carvalho e Nakagawa, 2000).

Conforme os dados expostos na Tabela 3, verificou-se que as sementes de funcho apresentaram diferentes índices de velocidade de germinação e houve efeito significativo entre os fatores analisados. Em presença de luz, observou-se maior velocidade de germinação na temperatura constante de $25^{\circ} \mathrm{C}$ e na alternada de $20-30^{\circ} \mathrm{C}$. Na ausência de luz, as sementes apresentaram menor índice de velocidade de germinação apenas na temperatura de $30^{\circ} \mathrm{C}$.

Em relação ao comprimento e a massa seca das plântulas de funcho verificou-se, através da análise da variância, que houve interação significativa entre os fatores analisados.

Os maiores comprimentos das plântulas foram observados, em presença de luz, nas temperaturas de 20 e $25^{\circ} \mathrm{C}$ e, na ausência de luz, na temperatura constante de $25^{\circ} \mathrm{C}$ e alternada de $20-30^{\circ} \mathrm{C}$. Na ausência de luz, apenas na temperatura de $30^{\circ} \mathrm{C}$ ocorreu desenvolvimento de plântulas menores (Tabela 4).

As plântulas de funcho apresentaram maior massa seca, em presença de luz, nas temperaturas de 20,25 e $20-30^{\circ} \mathrm{C}$ e na ausência de luz, não houve efeito dos tratamentos, em todas as temperaturas testadas (Tabela 4 ).

TABELA 3. Índice de velocidade de germinação de sementes de funcho, submetidas a diferentes temperaturas na presença e na ausência de luz. Santa Maria, RS. 2004.

\begin{tabular}{ccc}
\hline Temperatura & Presença de luz & Ausência de luz \\
\hline $20^{\circ} \mathrm{C}$ & $20,00 \mathrm{bB}^{*}$ & $25,50 \mathrm{aA}^{*}$ \\
$25^{\circ} \mathrm{C}$ & $22,75 \mathrm{aB}$ & $25,50 \mathrm{aA}$ \\
$20-30^{\circ} \mathrm{C}$ & $22,75 \mathrm{aA}$ & $23,75 \mathrm{aA}$ \\
$30^{\circ} \mathrm{C}$ & $9,50 \mathrm{cB}$ & $18,25 \mathrm{~b} \mathrm{~A}$ \\
\hline Média geral & & 21,00 \\
$\mathrm{CV}(\%)$ & 5,67 \\
\hline
\end{tabular}

* Médias seguidas de mesma letra, minúscula em cada coluna, e, maiúscula em cada linha, não diferem entre si, pelo teste de Tukey, a 5\% de probabilidade. 
TABELA 4. Comprimento $(\mathrm{cm})$ e massa seca das plântulas $(\mathrm{mg})$ de funcho, submetidas a diferentes temperaturas na presença e na ausência de luz. Santa Maria, RS. 2004.

\begin{tabular}{ccccc}
\hline \multirow{2}{*}{ Temperatura } & \multicolumn{2}{c}{ Comprimento das plântulas $(\mathrm{cm})$} & \multicolumn{2}{c}{ Massa seca das plântulas (mg) } \\
\cline { 2 - 5 } & Presença de luz & Ausência de luz & Presença de luz & Ausência de luz \\
\hline $20^{\circ} \mathrm{C}$ & $9,9 \mathrm{aA}^{*}$ & $8,2 \mathrm{abA}^{*}$ & $16,5 \mathrm{aA}^{*}$ & $13,2 \mathrm{aA}^{*}$ \\
$25^{\circ} \mathrm{C}$ & $8,5 \mathrm{abA}$ & $9,1 \mathrm{aA}$ & $19,5 \mathrm{aA}$ & $14,8 \mathrm{aA}$ \\
$20-30^{\circ} \mathrm{C}$ & $6,3 \mathrm{bA}$ & $9,0 \mathrm{aA}$ & $14,2 \mathrm{aA}$ & $18,2 \mathrm{aA}$ \\
$30^{\circ} \mathrm{C}$ & $2,4 \mathrm{cB}$ & $5,7 \mathrm{bA}$ & $1,3 \mathrm{bB}$ & $15,0 \mathrm{aA}$ \\
\hline Média geral & \multicolumn{3}{c}{} & 14,52 \\
CV $(\%)$ & 7,55 & & & 19,68 \\
\hline
\end{tabular}

* Médias, seguidas de mesma letra minúscula, em cada coluna, e letra maiúscula, em cada linha, não diferem entre si, pelo teste de Tukey, a $5 \%$ de probabilidade.

Desta forma, nas condições de luz e temperatura, observadas como as melhores no teste de germinação desta espécie, houve maior comprimento e massa seca das plântulas. Isto pode ser explicado porque, além de fornecidas as condições necessárias à germinação, as sementes vigorosas originam plântulas com maior taxa de crescimento, em função de apresentarem maior capacidade de transformação do suprimento de reservas dos tecidos de armazenamento e maior incorporação destes pelo eixo embrionário (Dan et al., 1987; Nakagawa, 1999).

Etapa II: Efeito do estresse hídrico no potencial fisiológico de sementes de funcho.

Os resultados do teste de estresse hídrico foram distintos em função do potencial hídrico a que as sementes foram expostas durante o período de germinação. Observou-se que à medida que diminuiu o potencial hídrico, houve redução da percentagem de germinação, do número de plântulas normais e da velocidade de germinação (Figura 1).

Este comportamento, pode ser explicado porque quando há restrições na disponibilidade hídrica, a absorção de água pela semente se torna lenta. A semente inicia a germinação e, não havendo água suficiente para a sua continuidade, pode haver o impedimento da emissão da raiz primária (Lopes et al., 1996) ou até a morte do embrião, conseqüentemente, reduzindo a percentagem de germinação final.

Em relação ao vigor das sementes de funcho, observouse que o estresse hídrico reduziu drasticamente a percentagem de plântulas normais aos sete dias após o início da germinação. Este fato tornou-se mais evidente nos potenciais osmóticos de -0,25MPa e -0,30MPa, uma vez que, nessas concentrações, não ocorreu a formação de plântulas normais na primeira contagem do teste de germinação. Além disso, verificou-se
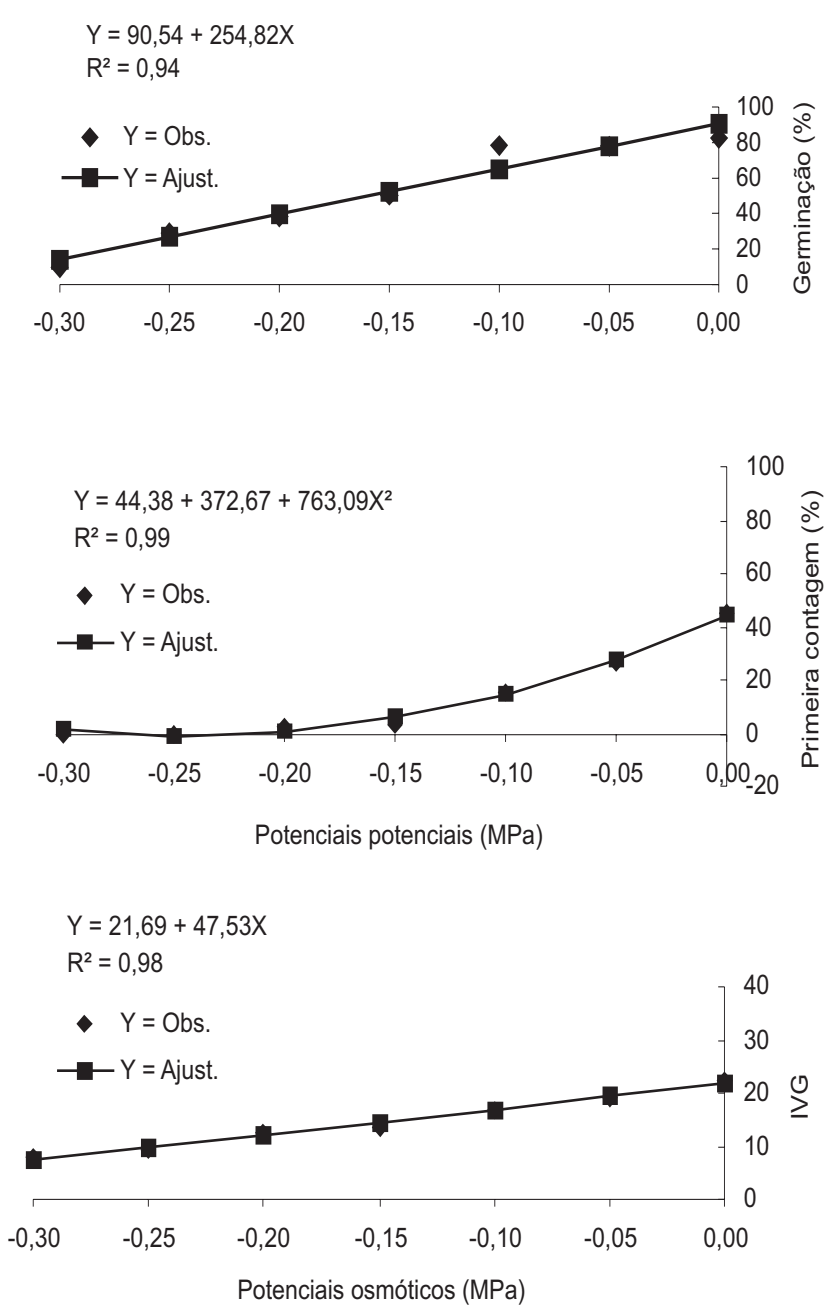

Figura 1. Percentagem de germinação, primeira contagem e índice de velocidade de germinação (IVG) de sementes de funcho submetidas a diferentes potenciais osmóticos em solução de polietileno glicol (PEG 6000). Santa Maria-RS, 2004. 
que o vigor das sementes de funcho foi mais afetado que a germinação, à medida que se aumentou a concentração das soluções osmóticas. Esta ocorrência, provavelmente, devese ao fato de que as sementes com qualidade inferior são mais afetadas pelo estresse hídrico (Razera, 1982).

\section{CONCLUSÕES}

A germinação de sementes de funcho ocorre tanto na presença quanto na ausência de luz.

As sementes de funcho germinam melhor nas temperaturas constantes de $20,25^{\circ} \mathrm{C}$ e alternada de $20-30^{\circ} \mathrm{C}$.

A temperatura de $30^{\circ} \mathrm{C}$ não é adequada para o teste de germinação nas sementes de funcho.

A diminuição dos potenciais osmóticos com polietileno glicol 6000 , a partir de $-0,1 \mathrm{MPa}$, reduz drasticamente a germinação e o vigor das sementes de funcho, sendo o vigor mais afetado que a germinação.

\section{REFERÊNCIAS}

ASSOCIATION OF OFFICIAL SEED ANALYSTS. Seed Vigor Testing Hanbook. Lincoln: AOSA, 1983. 88p.

BEWLEY, J.D.; BLACK, M. Seeds: physiology of development and germination. 2. ed. New York: Plenum, 1994. 445p.

BRASIL. Ministério da Agricultura e Reforma Agrária. Regras para análise de sementes. Brasília: SNDA/ DNDV/CLAV, 1992. $365 \mathrm{p}$.

CARDOSO, V.J.M. Germinação e fotoblastismo de sementes de Cucumis anguria: influência da qualidade da luz durante a maturação e secagem. Revista Brasileira de Fisiologia Vegetal, Brasília, v. 7, n.1, p.75-80, 1995.

CARNEIRO, J.W.P.; GUEDES, T.A. Influência da temperatura no desempenho germinativo de sementes de cenoura (Daucus carota L.), avaliada pela função de distribuição de Weibull. Revista Brasileira de Sementes, Brasília, v.14, n.2, p. 207-213, 1992.

CARVAlHO, N.M.; NAKAGAWA, J. Sementes: ciência, tecnologia e produção. 4 ed. Jaboticabal-SP: FUNEP, 2000. 588p.

COPELAND, L.O.; McDONALD, M.B. Principles of seed science and technology. 2. ed. New York: Macmillan, 1995. 321p.

DAN, E.L.; MELLO,V.D.C.; WETZEL, C.T.; POPINIGIS, F.; SOUZA, E.P. Transferência de matéria seca como modo de avaliação do vigor de sementes de soja. Revista Brasileira de Sementes, Brasília, v. 9, n. 3, p. 45-55, 1987.

IKUTA, A.R.Y.; BARROS, I.B.I. Influência da temperatura e da luz sobre a germinação de marcela (Achyrocline satureioides Lam.). Pesquisa Agropecuária Brasileira, Brasília, v.31, n.12, p.859-862, 1996.

LABOURIAU, L.G. A germinação das sementes. Washington:
OEA, 1983. 174p.

LOPES, H.M.; MARIA, J.; SILVA, R.F.; MALAVASI, M.M. Influência do potencial osmótico e da temperatura na embebição e no crescimento da radícula de sementes de cebola (Allium cepa L.). Revista Brasileira de Sementes, Brasília, v.18, n.2, p.167-172, 1996.

LORENZI, H.; MATOS, F.J.A. Plantas medicinais do Brasil: Nativas e Exóticas cultivadas. Nova Odessa, SP: Instituto Plantarum, 2002. 544p.

MAGUIRE, J.D. Speed of germination-aid in selection and evaluation for seedling emergence and vigor. Crop Science, Madison, v.2, n.2, p.176-177, 1962.

MARTINS, E.R.; CASTRO, D.M.; CASTELLANI, D.C.; DIAS, J.E. Plantas Medicinais. Viçosa: UFV, 1998. 220p.

MAYER, A.M.; POLJAKOFF-MAYBER, A. The germination of seeds. 2. ed. Oxford: Pergamon Press, 1989. 192p.

MENEGHELLO, G.E.; SCHNEIDER, S.M.H.; LUCCA FILHO, O.A. Veracidade da germinação indicada nas embalagens de sementes de espécies medicinais. Revista Brasileira de Sementes, Brasília, v.24, n.1, p.5-10, 2002.

MENEZES, N.L.; SANTOS, O.S.; NUNES, E.P.; SCHMIDT, D. Qualidade fisiológica de sementes de alface submetidas a diferentes temperaturas em presença e ausência de luz. Ciência Rural, Santa Maria, v.30, n.6, p.941-945, 2000.

MICHEL, B.E.; KAUFMANN, M.R. The osmotic potential of polyethylene glycol 6000. Plant Physiology, Lancaster, v.51, n.6, p.914-916, 1973.

NAKAGAWA, J. Testes de vigor baseados no desempenho de plântulas. In: KRZYZANOWSKI, F.C.; VIEIRA, R.D.; FRANÇA NETO, J.B. (Ed.) Vigor de sementes: conceitos e testes. Londrina: ABRATES. 1999.218p.

POLLOCK, B.M.; ROSS, E.E. Seed and seedling vigor. In: KOZLOWSKY, T.T., (Ed). Seed Biology. New York: Academic Press, 1972. p.313-387.

RAZERA, L.F. Emergence of soybean (Glycine max (L.) Merril) seed at various level of soil temperature and moisture. 1982. 83f. Tese (PhD. in the Departament of Agronomy) Mississipi State University, Mississipi, 1982.

STORCK, L.; GARCIA, D.C.; LOPES, S.J; ESTEFANEL,V. Experimentação Vegetal. Santa Maria: UFSM, 2000. 198p.

TAKAKI, M. New proposal of classification of seeds based on forms of phytochrome instead of photoblastism. Revista Brasileira de Fisiologia Vegetal, Brasília, v.13, n.1, p.103-107, 2001.

TAKARASHI, L.S.A.; SOUZA, J.R.P.; YOSHIDA, A.E. Germinação de sementes de erva-doce armazenadas em diferentes ambientes, embalagens e submetidas a períodos de embebição. Horticultura Brasileira, Brasília, v.18, p.937-938, 2000.

TEIXEIRA, M.S.; CUNHA, S.B.T.; MATTOS, M.B.; SANTANA, D.G.; RANAL, M.A. Número de sementes para teste de germinação de aquênios de erva-doce (Pimpinella anisum L.). In: XIII CONGRESSO BRASILEIRO DE SEMENTES, 13., 2003, Londrina. Anais... Londrina: ABRATES, 2003. p.408. 
VIDAVER, W.; HSIAO, A.I. Secundary dormancy in light sensitive lettuce seeds incubated anaerobically or at elevated temperature. Canadian of Botany, Ottawa, v. 53, p.2557-2560, 1975.

VILLELA, F.A.; DONI FILHO, L.; SIQUEIRA, E.L. Tabela de potencial osmótico em função da concentração de polietileno glicol 6000 e da temperatura. Pesquisa Agropecuária Brasileira, Brasília, v.26, n.11/12, p.1957-1968, 1991.

ZONTA, E.P.; SILVEIRA, P.S.; ALMEIDA, A. Sistema de Análises Estatísticas para Microcomputadores - SANEST. Pelotas: Instituto de Física e Matemática, UFPEL, 1986. 